\title{
Esthetic Considerations in Orthodontics: An Overview
}

\author{
Swati Singh ${ }^{1}$ Litesh Singla ${ }^{2}$ Tanya Anand ${ }^{3}$ \\ ${ }^{1}$ Consultant Orthodontist, Private Practice, New Delhi, India \\ 2Department of Orthodontics and Dentofacial Orthopedics, \\ Dr. Harvansh Singh Judge Institute of Dental Sciences and \\ Hospital, Panjab University, Chandigarh, India \\ ${ }^{3}$ B.R.S. Dental College and Hospital, Sultanpur, Panchkula, \\ Haryana, India
}

\begin{abstract}
Address for correspondence Litesh Singla, BDS, MDS, Department of Orthodontics and Dentofacial Orthopedics, Dr. Harvansh Singh Judge Institute of Dental Sciences and Hospital, Panjab University, Sector 25, Chandigarh 160014, India (e-mail: drlitesh@yahoo.com).
\end{abstract}

Swati Singh, BDS, MDS, Consultant Orthodontist, Private Practice, Z-20, Hauz Khas, New Delhi 110016, India (e-mail: swatisingh1209@gmail.com).

\begin{abstract}
Keywords

- macroesthetics

- microesthetics

- miniesthetics

Esthetics has been an ever-evolving concept and has gained considerable importance in the field of orthodontics in the last few decades. The re-emergence of the soft tissue paradigm has further catapulted the interest of the orthodontist. So much so that achieving a harmonious profile and an esthetically pleasing smile has become the ideal goal of treatment and is no longer secondary to achieving a functional dental occlusion and/or a rigid adherence to skeletal and dental norms. Esthetics in the orthodontic sense can be divided into three categories: macroesthetics, miniesthetics, and microesthetics. Macroesthetics includes the evaluation of the face and involves frontal assessment and profile analysis. The frontal assessment involves assessment of facial proportions, while the profile analysis involves evaluation of anterior-posterior position of jaws, mandibular plane, and incisor prominence and lip posture. Miniesthetics involves study of the smile framework involving the vertical tooth-lip relationship, smile type, transverse dimensions of smile, smile arc, and midline. Microesthetics involves the assessment of tooth proportions, height-width relationships, connectors and embrasures, gingival contours and heights, and tooth shade and color. The harmony between these factors enables an orthodontist to achieve the idealized esthetic result and hence these parameters deserve due consideration. The importance placed on a pleasing profile cannot be undermined and the orthodontist should aim for a harmonious facial profile over rigid adherence to standard average cephalometric norms. This article aims to give an overview of the macro, mini, and microesthetic considerations in relation to orthodontic diagnosis and treatment planning.
\end{abstract}

\section{Introduction}

The importance of esthetics in the orthodontic sense can hardly be overemphasized, yet, it has often been considered secondary to achieving an ideal functional occlusion. Edward H. Angle based his ideal of harmony on the Greek facial Type of Apollo Belverde and believed that a "full complement of teeth" was indispensable for achieving perfect

DOI https://doi.org/ $10.1055 / \mathrm{s}-0041-1726473$ ISSN 2321-1482. harmony and this belief predominated in the orthodontic world for a few decades. ${ }^{1}$ Angle's belief was challenged by practitioners like Case, Tweed, and Begg who were dissatisfied by the instability and lack of esthetics following the overzealous adherence to the nonextraction philosophy and started advocating need based extractions so as to achieve esthetic harmony. ${ }^{1,2}$

(c) 2021. Bhojia Dental College and Hospital affiliated to Himachal Pradesh University.

This is an open access article published by Thieme under the terms of the Creative Commons Attribution-NonDerivative-NonCommercial-License, permitting copying and reproduction so long as the original work is given appropriate credit. Contents may not be used for commercial purposes, or adapted, remixed, transformed or built upon. (https://creativecommons.org/licenses/by-nc-nd/4.0/). Thieme Medical and Scientific Publishers Pvt. Ltd. A-12, 2nd Floor, Sector 2, Noida-201301 UP, India 
The definition of an ideal is subjective and is dependent on collective and individual esthetic judgements. The "ideal seat of proportions" has been described with various sources of reference-artistic, cephalometric, and anthropometric. Attitudes to attractiveness are assimilated from early childhood through contemporary culture, indoctrination as well as a genetic origin. ${ }^{3}$ Research has shown that the perception of attractiveness is both inherent and universal. Studies by Bernstein et $\mathrm{al}^{4}{ }^{4}$ Thakera and Iwawaki, ${ }^{5}$ Maret and Harling, ${ }^{6}$ and Langolis et $\mathrm{al}^{7}$ have found significant cross-cultural agreement between what is considered attractive.

Esthetics has become imperative so as to achieve a satisfactory outcome and is now an indispensable part of the idealized treatment goal. As the perception of esthetics is different for the orthodontist from that of a layperson, the patient's perception of the face must be acknowledged prior to commencing treatment. ${ }^{8,9}$ Moreover, the treatment goals should aim for a balanced and harmonious facial profile over rigid adherence to standard average skeletal and dental norms. ${ }^{10}$

\section{Assessment of Dentofacial Esthetics}

The basic requirements for assessment of the dentofacial esthetics include a dynamic and static three-dimensional evaluation of the face during clinical evaluation, determination of the lip tooth relationship and anterior tooth display (during rest and facial animation), as well as an analysis of the effect of the dental and skeletal volume on the surrounding soft tissue. ${ }^{2}$

The three esthetic divisions evaluated in orthodontic diagnosis are as follows:

Macroesthetics: It includes assessment of facial proportions in all three planes of space.

Miniesthetics: It includes the assessment of the relationship of the dentition to the face (tooth-lip relationship and smile analysis).

Microesthetics: This determines the relationship of teeth to each other. ${ }^{11}$

\section{Macroesthetics}

Evaluation is done both in frontal as well as lateral (profile) view.

\section{Frontal Assessment}

Assessment is done for any asymmetry in the frontal plane. An ideally proportioned face can transversely be divided into equal central, medial, and lateral fifths. The separation of the eyes and the width of the eyes, determined by the central and medial fifths, should be equal. The nose and chin should be contained within the central fifth, with the width of the nose equal to or slightly wider than the central fifth. Ideally, the interpupillary distance should be same as the width of the mouth. Vertical facial proportions in the frontal and lateral views are best assessed in relation to the facial thirds, which should ideally be equal in height in well-proportioned faces ( - Fig. 1A, B). ${ }^{11}$ Ricketts $^{12,13}$ advocated the used of golden

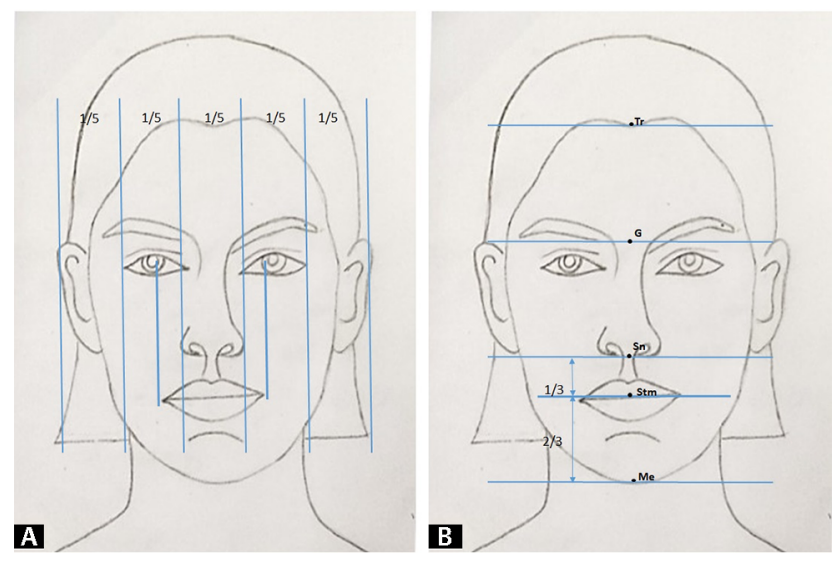

Fig. 1 Frontal proportions: (A) Transverse and (B) vertical (original). G, glabella; Me, menton; Sn, subnasale, Stm, stomion, Tr, trichion.

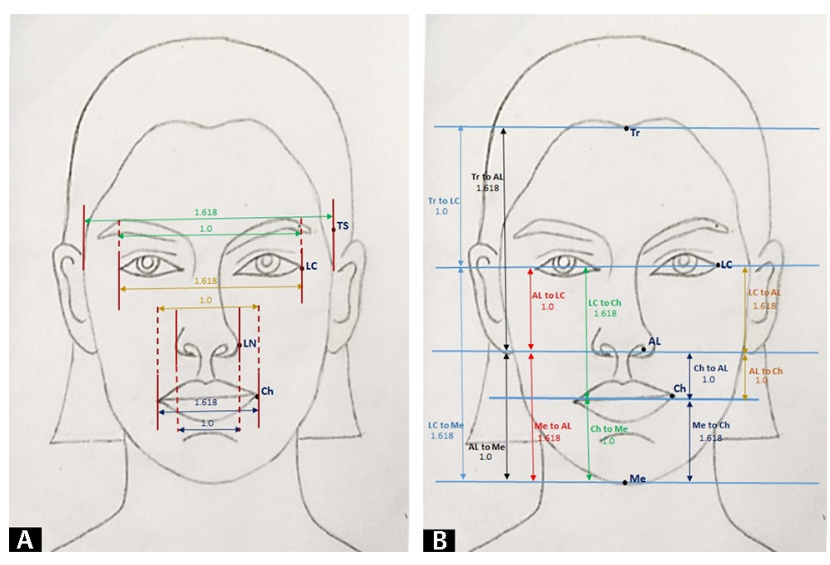

Fig. 2 Golden proportions of face: (A) Transverse proportions and (B) vertical proportions (original). AL: alar rim; Ch, chelion; LC, lateral canthus; LN, lateral side of nose; Me, menton; Tr, trichion; TS, width of the head at the temporal soft tissue.

proportion for the analysis of a physically beautiful face (-Fig. 2). The golden proportion is mathematically defined as phi and is equal to 1.618 . This relationship is universal regardless of age, sex, and race and has been displayed in the face as well as dentition. Anthropometric studies have established facial measurements to serve as a guide in diagnosis and treatment planning. ${ }^{14}$

\section{Profile Assessment}

It involves the following parameters:

Anteroposterior position of jaws: The estimation of the profile, that is, convex, concave, and straight, serves as a guide to determine the underlying skeletal relationship and whether the jaws are proportionately positioned in the anteroposterior plane. ${ }^{11}$

The treatment modalities for dentoskeletal corrections range from growth modification (through dentofacial orthopaedic and functional therapy), camouflage treatment (through extraction and non-extraction therapy), and orthognathic surgery in severe discrepancies. Advancements in computer imaging have enabled the orthodontist to plan and execute the treatment of an orthognathic patient effectively along with establishing realistic goals. Depending on the 
severity of the dentofacial deformity and esthetic demands, a variety of surgical options like maxillary advancement, maxillary alveolar setback, maxillary superior repositioning, mandibular advancement, mandibular setback, and adjuvant soft tissue surgical procedures (genioplasty, rhinoplasty, and cheiloplasty) can be used to achieve optimal dentoskeletal as well as facial esthetics.

Vertical proportions and mandibular plane: Assessment of the vertical facial thirds and the mandibular plane in the lateral view helps in unmasking the vertical growth tendencies. A steep mandibular plane angle is associated with long anterior facial height and a skeletal open bite tendency, whereas a flat mandibular plane angle usually accompanies a short anterior facial height and deep bite malocclusion. ${ }^{11}$

Assessment of the incisor prominence and lip posture: Relationship between incisor prominence and lip posture aids in the formulation of a treatment plan. The ideal position of the incisors to their supporting bone is determined by components like the relationship of the jaws, soft tissue contours, and the relationship of the incisors to the supporting bone. ${ }^{15}$

Excessive protrusion of incisors is determined by prominent lips, separated by more than 3 to $4 \mathrm{~mm}$ in relaxed position, that have to be strained to achieve closure. ${ }^{11}$ Retraction of teeth in such a patient will aid in improving lip function as well as facial esthetics and hence extractions should be considered in cases having bimaxillary protrusion (or protrusion) with/without crowding. Retraction of maxillary incisors reduces upper lip prominence but should not be done to an extent that the inclination of the upper lip becomes negative in relation to the true vertical line (an imaginary plum line at the intersection of the philtrum of the lip to the subnasale). ${ }^{15}$ The profile is flattened by $\sim 2 \mathrm{~mm}$ by premolar extraction and the dishing in of the profile can be attributed to faulty diagnosis and planning. ${ }^{16}$ Burston $e^{17}$ has stated that a decrease in lip prominence following retraction occurs only till lips close at rest without strain. However, when prominent lips close without strain, then the dentition is not at fault and retraction in such cases would provide no benefit apart from making the nasolabial angle more obtuse. ${ }^{18}$

The relative prominence of the nose and chin in relation to the lips and face is important in treatment planning. In patients with a large nose and/or a large chin, a greater degree of lip prominence (achieved by incisor protraction) would still be considered esthetic. ${ }^{15}$

Surgical intervention is required sometimes for achieving optimal esthetic results in cases with mandibular retrusion/ protrusion. In Class II Div. 1 cases having lower lip trap with an increased overjet, proclined upper lip, and acute nasolabial angle, retraction of maxillary incisors improves lip seal and esthetics. However, when the upper lip is aesthetically positioned and the nasolabial angle is obtuse, mandibular advancement needs to be considered. In Class II camouflage cases with everted lower lip due to excessive proclination of mandibular incisors relative to the chin, the ideal treatment option would be incisor retraction by premolar extraction or genioplasty. ${ }^{15}$
In cases with mandibular prognathism, having an increased lower facial height with protruded teeth, lack of a well-defined labiomental sulcus can be corrected by retraction of incisors. In patients having a Class III profile and thin lips, proclining the incisors tend to improve the profile by creating fuller lips. ${ }^{15}$

\section{Miniesthetics}

\section{Smile Type and Vertical Tooth-Lip Relationship}

For an esthetically pleasing social smile, at least $75 \%$ of the maxillary crown should be visible, but up to $4 \mathrm{~mm}$ display of gingiva/4 $\mathrm{mm}$ lip coverage of the incisor crown is acceptable. ${ }^{11}$ The most attractive smiles have the upper lip at the height of the gingival margin of the upper central incisor. ${ }^{19}$ Three smile types have been described by Tjan et al ${ }^{20}$ based on amount of incisor and gingival display: low, average, and high (-Fig. 3). The average smile displays 75 to $100 \%$ of the maxillary crown length, the low smile shows less than $75 \%$ crown, while the high smile or the "gummy smile" is categorized by the display of the entire crown length in addition to a contiguous band of gingiva. ${ }^{21}$

In cases of low smile types, elongating the upper teeth can be achieved by arch wires, anterior vertical elastics, judicious use of Class II elastics (which can rotate the occlusal plane down anteriorly), and the help of orthognathic surgery. ${ }^{11}$ In some cases, a combination of orthodontics and prosthetic crown lengthening with porcelain laminate veneers may be suggested. ${ }^{21}$

In cases of a high smile type, the underlying cause might be anterior vertical excess, increased muscular capacity to raise the upper lip, excessive overjet and overbite, and excessive interlabial gap at rest. Treatment modalities for correction of a high smile type include segmented arch mechanics for intrusion of maxillary incisors, intrusion using temporary anchorage devices, and orthognathic surgery (Lefort I Osteotomy)..$^{1}$ Orthognathic surgery needs to be considered in cases having vertical maxillary excess without excessive exposure of maxillary teeth in repose, as orthodontic treatment may accentuate the problem by over retraction of maxillary incisors or anterior tilting of the occlusal plane. ${ }^{15}$ In cases with adequate incisor display and deep bite with a deep curve of Spee, active intrusion of mandibular incisors is desirable, while molar extrusion may be considered in normal and low angle cases. ${ }^{21}$ Incisor display at rest and during smile reduces with flaring, while increased display is seen with uprighting of incisors. ${ }^{22}$

However, overzealous maxillary intrusion can lead to an older appearance and a gummy smile is considered more youthful than diminished tooth display. ${ }^{21}$ Between

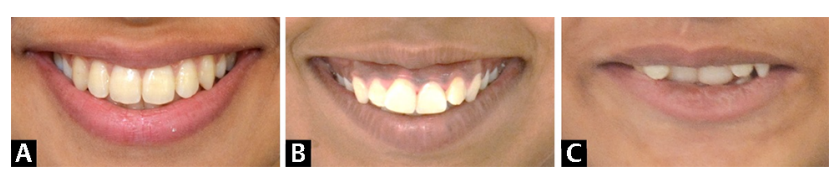

Fig. 3 Smile types: (A) Average smile, (B) high smile, and (C) low smile (original). 
the third to seventh decades of life, maxillary incisor exposure decreases by $3.4 \mathrm{~mm}$ and mandibular incisor exposure increases by $2.4 \mathrm{~mm} .{ }^{23}$ As a person ages, smile becomes narrower vertically and wider transversely. ${ }^{24}$

\section{Transverse Dimension of Smile}

Buccal corridor and arch form: The buccal corridor is a space created between the buccal surface of the posterior teeth and the corner of the lips when the patient smiles. ${ }^{25}$ The presence of buccal corridors is considered to give a natural appearance. The transverse width of the arch should be esthetically related to the facial width. Pretreatment mandibular intercanine width and mandibular arch form should serve as the optimal guide to future dental arch form and stability.

A narrow collapsed arch form presents inadequate transverse dimension characteristics and dramatic improvements in aesthetics are seen after orthodontic treatment. ${ }^{22}$ Noticeably constricted maxillary arch with or without cross bites requires expansion. Smile fullness can be added intentionally by adding buccal crown torque to palatally inclined canines and premolars in case the maxillary arch is satisfactory in regard to shape and width. ${ }^{21}$ However, patients having buccally flared posteriors should not undergo expansion. ${ }^{11}$ Excessive intentional expansion results in obliteration of the buccal corridor leading to a denture like smile, flattening of the smile arc, and disequilibrium and long-term relapse. ${ }^{21}$

Studies have suggested that large buccal corridors give rise to less attractive smiles. ${ }^{26}$ Measurement of buccal corridors in extraction and nonextraction cases has yielded no significant differences. ${ }^{27}$

Transverse cant and symmetry: Discrepancy in the maxillary anterior incisal plane depends on the interaction between posterior occlusal plane, incisal plane, interpupillary line, and crown length of the maxillary incisors. If the maxillary incisal plane deviates from the interpupillary line but coincides with the occlusal plane, the entire maxilla is developed asymmetrically and maxillary surgery is advised to intrude the maxilla on the over erupted side. When the maxillary incisal plane deviates from the interpupillary line and the occlusal plane, orthodontic extrusion/intrusion is performed. ${ }^{28}$ Smile asymmetry may also result due to asymmetric smile curtain. ${ }^{22}$ In preadolescents, the occlusal plane can be corrected by growth modification appliances but in the adolescent and adult patients surgery is often indicated. ${ }^{22}$ Individualized, esthetic, symmetric labiolingual crown inclinations are to be the treatment goal for every patient. ${ }^{21}$

\section{Smile Arc}

It is defined as the relationship of the curvature of the incisal edges of the maxillary incisors and canines to the curvature of the lower lip in a posed smile. ${ }^{29}$ Three types of smile arcs are seen: parallel (consonant), straight, and reverse smile arc, with the goal being a parallel smile arc. ${ }^{21}$ In the parallel arc, the incisal curve follows the lower lip while it is flatter in the straight arc. In the reverse arc, the canines are lower and the arc is reverse to the curve of the lower lip ( - Fig. 4). Ideally a distance of 1 to $1.5 \mathrm{~mm}$ between the central and lateral incisal edges/bracket slots is ideal, while the traditional $0.5 \mathrm{~mm}$

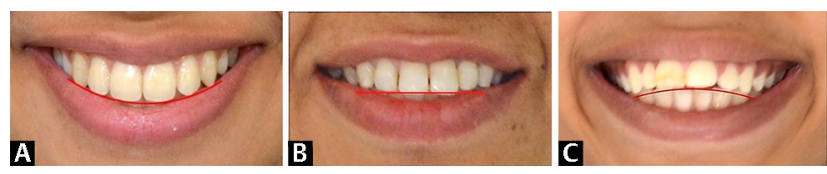

Fig. 4 Smile arcs: (A) Parallel (consonant) smile arc, (B) straight smile arc, and (C) reverse smile arc (original).

difference in the bracket slot between the central and lateral incisor leads to a flat smile. ${ }^{22}$ Step bends in the archwire can also be used to achieve this goal.

\section{Midline}

During direct frontal examination, the maxillary midline should at least be ideally vertical and parallel to the facial midline if not coincident, which is ideal. Orthodontists can detect midline deviations greater than $2.2 \mathrm{~mm}$, while the range is as high as $3 \mathrm{~mm}$ for laypersons. ${ }^{26}$ However, when the maxillary midline is angulated even a $2 \mathrm{~mm}$ ( 10 degrees), deviation will be perceptibly unattractive. ${ }^{30}$ Eventhough coinciding maxilla-mandibular midlines are ideal but for functional reasons the mandibular midline is not that grave an esthetic concern. ${ }^{21}$

\section{Microesthetics}

\section{Tooth Proportions}

For an esthetically pleasing smile according to the golden proportion, the apparent width of the lateral incisor should be $62 \%$ of the width of the central incisor, the apparent width of the canine should be $62 \%$ that of the lateral incisor and the apparent width of the first premolar should be $62 \%$ that of the canine ( $\mathbf{- F i g}$. 5A). This ratio serves as a guide to determine the post-treatment size of a lateral size in case of disproportionately small lateral incisors, or when canines are reduced to replace the lateral incisors in case of congenitally missing laterals. ${ }^{11}$ As smile after extraction treatment has been shown to deviate from the golden proportion ratios more than nonextraction treatment, microesthetics need to be duly preserved in such treatment. ${ }^{31}$

\section{Height-Width Relationships}

The width of a tooth should be $80 \%$ of the height. ${ }^{11}$ Sterrett et $\mathrm{a}^{32}$ have given an ideal range of 0.75 to 0.85 . The central incisor may have a width of 8.1 to $8.6 \mathrm{~mm}$ and a length of 9.5 to $10.2 \mathrm{~mm}$ ( - Fig. 5B)..$^{33}$ Teeth appear tapered when height is excessive and square when it is deficient. Sulcular depth of the incisors, lip level, relative crown length and amount of incisal wear influence the treatment strategy in cases with disproportionate length. ${ }^{34}$ In case of reduced crown height, the restoration of the missing part of the crown is done through laminates or bonding, while facial laminates are used in cases of distorted crowns and periodontal crown lengthening is performed in cases with vertical gingival encroachment. ${ }^{11}$

\section{Connectors and Embrasures}

Connector area is defined as the interdental contact area, while embrasures are defined as the triangular spaces that 


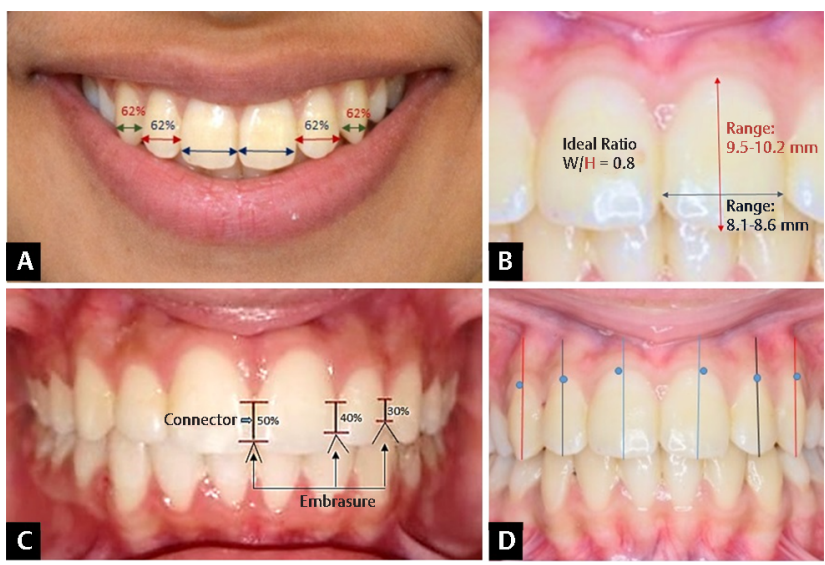

Fig. 5 Microesthetics: (A) Tooth proportions, (B) height-width relationship, (C) connectors and embrasures, and (D) gingival zeniths (original).

lie incisal to the contact. ${ }^{35}$ The contact points move gingivally from the central incisors to the premolars, leading to a progressively larger incisal embrasure. Ideally, the maxillary anterior teeth follow the 50-40-30 ratio with the ideal connector length between the two maxillary incisors being $50 \%$ of the crown length and so on ( - Fig. 5 C). ${ }^{36}$ The embrasures are generally larger in size to the connectors and the interdental papilla fills the gingival embrasure. When the interdental papillae are short, open gingival embrasures are present above the connectors forming unaesthetic black triangles. Orthodontic treatment of adults with severely crowded/rotated maxillary incisors as well as periodontal disease may cause black triangles. Reshaping the teeth by interproximal stripping and orthodontic root paralleling followed by space closure is the treatment of choice. ${ }^{11}$ Patients having a potential for black triangles have to be briefed about the need of reshaping of teeth to correct the same.

\section{Gingival Height, Shape, and Contour}

Proportionate gingival height is indispensable for an esthetic dental appearance. Generally, the central incisor and canine gingival margin are at the same level, while the lateral incisor margin is $1.5 \mathrm{~mm}$ lower. When the canines replace the laterals, this fact should be kept in mind. ${ }^{11}$ The gingival shape of the maxillary central incisors and canines is elliptical and the gingival zenith is oriented distal to the long axis of the respective tooth. The gingival shape of the maxillary lateral incisors and mandibular incisors should be symmetric half oval/half circle with the gingival zenith coinciding with the

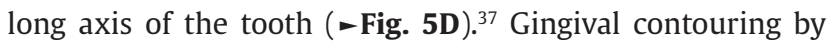
removal of excess gingiva is accomplished through periodontal surgeries like gingivectomy or crown lengthening, while gingival recession is routinely treated with tissue grafts or guided tissue regeneration and in some cases by nonsurgical orthodontic extrusion. ${ }^{33}$

\section{Tooth Shade and Color}

A progression of shade from the midline posteriorly leads to an esthetically pleasing smile. The maxillary central incisors are the lightest and brightest and the teeth become gradually less bright. The hue (color) of maxillary laterals is similar to the central incisors but they are less bright. The canines are the least bright teeth with the highest chroma (color saturation). The first and second premolars are however closer to the laterals in color and hence are brighter than the canines. ${ }^{33}$ The teeth become dull and dark with age due to the formation of secondary dentin and wearing away of the facial enamel. ${ }^{11}$

\section{Conclusion}

The re-emergence of the soft tissue paradigm has shifted the focus of orthodontics from merely establishing ideal occlusion to a more integrated approach where esthetics are as much a concern as dentofacial correction, if not more. With the turn of the century, the importance placed on a pleasing profile cannot be undermined and hence it is imperative for the practitioner to choose treatment modalities that result in a significant improvement in the overall facial as well as dental esthetics of the patient.

Conflict of Interest

None declared.

\section{References}

1 Turley PK. Evolution of esthetic considerations in orthodontics. Am J Orthod Dentofacial Orthop 2015;148(3):374-379

2 Sarver DM, Ackerman JL. Orthodontics about face: the re-emergence of the esthetic paradigm. Am J Orthod Dentofacial Orthop 2000;117(5):575-576

3 Edler RJ. Background considerations to facial aesthetics. J Orthod 2001;28(2):159-168

4 Bernstein IH, Lin TD, McClellan P. Cross- vs. within-racial judgments of attractiveness. Percept Psychophys 1982;32(6): 495-503

5 Thakerar JN, Iwawaki S. Cross-cultural comparisons in interpersonal attraction of females toward males. J Soc Psychol 1979;108(1):121-122

6 Maret SM, Harling CA. Cross-cultural perceptions of physical attractiveness: Ratings of photographs of whites by Cruzans and Americans. Percept Mot Skills 1985;60(1):163-166

7 Langlois JH, Kalakanis L, Rubenstein AJ, Larson A, Hallam M, Smoot M. Maxims or myths of beauty? A meta-analytic and theoretical review. Psychol Bull 2000;126(3):390-423

8 Peck H, Peck S. A concept of facial esthetics. Angle Orthod 1970;40(4):284-318

9 Peck S, Peck L. Selected aspects of the art and science of facial esthetics. Semin Orthod 1995;1(2):105-126

10 Czarnecki ST, Nanda RS, Currier GF. Perceptions of a balanced facial profile. Am J Orthod Dentofacial Orthop 1993; 104(2):180-187

11 Proffit WR, Fields HW, Sarver DM, Contemporary Orthodontics. 5th edition. St. Louis, MO: Elsevier, Mosby; 2012

12 Ricketts RM, Facial art, the divine proportion and the science of esthetics. In: Ricketts RM. ed. Provocations and Perceptions in Craniofacial Orthopedics, Vol 1. Boulder, CO: RMO; 1989: 149-202

13 Ricketts RM. The biologic significance of the divine proportion and Fibonacci series. Am J Orthod 1982;81(5):351-370

14 Farkas LG, Anthropometry of the Head and Face in Medicine. 2nd edition. New York: Raven Press; 1994

15 Ackerman JL, Proffit WR. Soft tissue limitations in orthodontics: treatment planning guidelines. Angle Orthod 1997; 67(5):327-336 
16 Bowman SJ. More than lip service: facial esthetics in orthodontics. J Am Dent Assoc 1999;130(8):1173-1181

17 Burstone CJ. Lip posture and its significance in treatment planning. Am J Orthod 1967;53(4):262-284

18 Mejia-Maidl M, Evans CA. Soft tissue facial considerations and orthodontic treatment. Semin Orthod 2000;6(1):3-20

19 Hulsey CM. An esthetic evaluation of lip-teeth relationships present in the smile. Am J Orthod 1970;57(2):132-144

20 Tjan AH, Miller GD, The JG. Some esthetic factors in a smile. J Prosthet Dent 1984;51(1):24-28

21 Zachrisson BU, Esthetics in tooth display and smile design. In Nanda R, ed. Biomechanics and Esthetic Strategies in Clinical Orthodontics. St. Louis, MO: Elsevier Saunders; 2005: 110-130

22 Sarver DM, Ackerman MB. Dynamic smile visualization and quantification: Part 2. Smile analysis and treatment strategies. Am J Orthod Dentofacial Orthop 2003;124(2):116-127

23 Vig RG, Brundo GC. The kinetics of anterior tooth display. J Prosthet Dent 1978;39(5):502-504

24 Desai S, Upadhyay M, Nanda R. Dynamic smile analysis: changes with age. Am J Orthod Dentofacial Orthop 2009;136(3):310. e1-310.e10

25 Frush JP, Fisher RD. The dynesthetic interpretation of the dentogenic concept. J Prosthet Dent 1958;8(4):558-581

26 Janson G, Branco NC, Fernandes TM, Sathler R, Garib D, Lauris JR. Influence of orthodontic treatment, midline position, buccal corridor and smile arc on smile attractiveness. Angle Orthod 2011;81(1):153-161

27 Christou T, Betlej A, Aswad N, Ogdon D, Kau CH. Clinical effectiveness of orthodontic treatment on smile esthetics: a systematic review. Clin Cosmet Investig Dent 2019;11:89-101
28 Kokich V. Esthetics and anterior tooth position: an orthodontic perspective. Part II: Vertical position. J Esthet Dent 1993;5(4):174-178

29 Sarver DM. The importance of incisor positioning in the esthetic smile: the smile arc. Am J Orthod Dentofacial Orthop 2001;120(2):98-111

30 Kokich VO Jr, Kiyak HA, Shapiro PA. Comparing the perception of dentists and lay people to altered dental esthetics. J Esthet Dent 1999;11(6):311-324

31 Tauheed S, Shaikh A, Fida M. Microaesthetics of the smile: extraction vs. non-extraction. J Coll Physicians Surg Pak 2012;22(4):230-234

32 Sterrett JD, Oliver T, Robinson F, Fortson W, Knaak B, Russell CM. Width/length ratios of normal clinical crowns of the maxillary anterior dentition in man. J Clin Periodontol 1999;26(3):153-157

33 Sharma PK, Sharma P. Dental smile esthetics: the assessment and creation of the ideal smile. Semin Orthod 2012;18(3):193-201

34 Kovich V. Esthetics and anterior tooth position: an orthodontic perspective. Part I: crown length. J Esthet Dent 1993;5(1):19-23

35 Sarver DM. Principles of cosmetic dentistry in orthodontics: Part 1. Shape and proportionality of anterior teeth. Am J Orthod Dentofacial Orthop 2004;126(6):749-753

36 Morley J, Eubank J. Macroesthetic elements of smile design. J Am Dent Assoc 2001;132(1):39-45

37 Gurel G. The Science and Art of Porcelain Laminate Veneers. London: Quintessence Publishing (IL); 2003 